Accepted for publication in the Journal of Semantics, pre-final version, February 2007. 


\title{
The ingredients of reciprocity in Cuzco Quechua
}

\author{
Martina Faller \\ The University of Manchester
}

\begin{abstract}
In Cuzco Quechua reciprocity is marked by means of two verbal suffixes, one of which is a marker of reflexivity, the other of which is a marker of pluractionality. The paper develops an analysis that composes reciprocity from these more basic notions. Two further ingredients that are needed will be argued to derive from independent principles: universal quantification over parts of the reciprocal plural agent derives from plural predication, as has been argued by other researchers for English reciprocity; distinctness of the participants in the reciprocal subevents derives from a semantic version of Condition B. This way of composing reciprocity is not universal, other languages have dedicated reciprocal markers or make other reciprocal ingredients overt. The compositional derivation of reciprocity is therefore a clear candidate for cross-linguistic semantic variation.
\end{abstract}

\section{Introduction}

This paper develops a compositional analysis of reciprocity in Cuzco Quechua (CQ) with the aim of elucidating the question of how languages may differ in the compositional derivation of this complex semantic notion. In a wider sense, it is a contribution to the growing literature on the possible space of cross-linguistic semantic variation. Consider the following Quechua reciprocal sentence and its English translation.

(1) Hayt'a-na-ku-n-ku

kick-PA-REFL-3-PL

'They kick each other.'

Both entail that there are at least two kicking events, that the agent and the theme of each kicking event are distinct but drawn from the same group consisting of at least two members (namely the group denoted by they, which serves as the antecedent for the pronominal each other), and that each of the members of this group is an agent of at least one of these events and a theme of at least another one. In general, reciprocity is a complex concept that encompasses the more primitive notions of plurality, distinctness of coarguments, reflexivity, and universal quantification over parts of the reciprocal agent. While reciprocal 
sentences in the two languages share these semantic features, they are very different morphosyntactically: English employs the nominal bipartite anaphor each other, CQ employs two verbal suffixes: - na, which I will argue is a pluractional marker, and $-k u$, a reflexive. The main question for typological semantics that is raised by these observations is how the cross-linguistically uniform semantics is derived from the rather different morphosyntactic realizations, a question first raised in the formal literature by Dalrymple et al. (1994). The CQ data is interesting in this respect because its reciprocal construction is not like other verbal reciprocals discussed in the literature (Bruening 2006, Mchombo 1993, Siloni to appear) in that it involves two morphemes rather than just one and thus raises the possibility that reciprocity is derived compositionally in this language. Dalrymple et al. (1994) studied the Chichewa monomorphemic verbal reciprocal and found that it shares the same cluster of semantic features as English reciprocal sentences; in addition to the features mentioned above, Chichewa and English reciprocals also have in common that they give rise to scope ambiguities when embedded. Dalrymple et al. (1994) concluded that the best way to deal with this semantic uniformity in the face of morphosyntactic diversity is to assume that any reciprocal construction is lexically specified as having reciprocal semantics. More precisely, they argued that reciprocal constructions denote RECIP, a polyadic quantifier, the semantics of which are such that it entails all of the above features. The language-specific morphosyntactic realization of this quantifier is therefore largely semantically irrelevant. In particular, they argued that an account such as Heim et al.'s (1991) which composes reciprocity from a universal quantifier (each) and a so-called reciprocator (other) is not viable cross-linguistically as it cannot account for the fact that Chichewa reciprocal sentences have the same properties as their English counterparts despite not employing two morphemes that could be analyzed as a universal quantifier and a reciprocator. ${ }^{1}$ While I agree with the conclusion that Heim et. al's (1991) or any other compositional approach to the semantics of each other will not necessarily be applicable to reciprocals in other languages, not even other bipartite reciprocals, this does not necessitate an approach that associates reciprocal semantics directly with a morphosyntactically complex construction. In this paper, I will explore a different approach. It starts from the observation that the semantics of reciprocity is inherently complex. Even when one assigns a universal meaning such as RECIP to a reciprocal construction, one nevertheless has to require that this meaning has the components of plurality, universal quantification and distinctness of coarguments somehow bundled into it. It therefore should be equally possible to derive the universal features of reciprocity by composing two or more markers which have these more basic notions as their meaning. Thus, the observation that reciprocal constructions across languages share a number of features does not exclude the possibility that these features are derived compositionally in some languages. I will argue that CQ is

\footnotetext{
${ }^{1}$ In order to account for the morphosyntactic diversity of reciprocal constructions Dalrymple et al. (1994:157) hypothesize "that linguistic universals governing the interpretive relation between morphosyntax and meaning explain the naturalness of the quite different forms of expression English and Chichewa choose for reciprocal propositions."
} 
such a language. Given languages like Chichewa with dedicated reciprocals, it follows that there is cross-linguistic variation in the way the complex semantic notion of reciprocity is composed (or not) from more basic building blocks.

I will not enter the debate about what the best analysis of English each other is. But I will take my cue for developing an analysis of CQ reciprocal sentences from a third approach to English reciprocals, which neither tries to derive reciprocity compositionally from the meaning of each and other, nor claims that each other directly denotes all features of reciprocity. Instead, this approach treats reciprocal sentences as special instances of relational plurals and argues that most semantic properties of reciprocal sentences follow from their plural properties (Langendoen 1978, Sternefeld 1998, Beck 2001). In particular, universal quantification over parts of the subject group is a direct consequence of plural predication and the definition of plural thematic roles. The overtly marked ingredients for reciprocity in CQ will be shown to be pluractionality $(-n a)$, and reflexivity $(-k u)$.

Most, if not all previous accounts of reciprocity assume that the requirement that the arguments of the reciprocal subevents are distinct is encoded by the reciprocal construction itself. This paper departs from this assumption and instead explores the possibility that the distinctness requirement corresponds to a general condition on semantic predicates requiring coarguments to be distinct (Reinhart and Reuland 1993).

The paper is organized as follows. Section 2 presents the CQ data to be accounted for and motivates an analysis of $-n a$ as a pluractional marker. Section 3 introduces the notion of cumulativity and how it has been used to account for reciprocity in English. Section 4 develops a formal account of simple reciprocal sentences in CQ based on the notions of pluractionality, reflexivity, and cumulativity, and suggests that the distinctness condition is a direct consequence of a semantic formulation of Condition B. Section 5 concludes and raises some issues to be investigated in the future.

A note on reciprocal truth conditions. Before proceeding with the main purpose of this paper, I should clarify that it is not my intention to contribute to the ongoing debate on how many truth-conditionally distinct reciprocal readings should be recognized. This question has still not been settled for English. For example, Langendoen (1978) considers six truth-conditionally distinct readings for elementary reciprocal sentences (ERS, those in which each other occupies the second argument position of a two-place relation $\mathrm{R}$ ), but rejects five of these as generally adequate in favor of just one, Weak Reciprocity. An ERS with relation $x R y$ and $A$ as the denotation of the plural subject is true according to Weak Reciprocity if (2) holds:

(2) Weak Reciprocity

$$
(\forall x \in A)(\exists y, z \in A)(x \neq y \wedge x \neq z \wedge x R y \wedge z R x)
$$

(Langendoen 1978:179)

Under this reading, (1) is true if each member of the group denoted by 'they' kicks at least one other member of that group and is kicked by at least one other 
member. This is weaker than strong reciprocity which would require every pair of individuals in the subject group to be in the kicking relation, but this is in accordance with the intuitions of most speakers, who would not consider (1) false in a situation in which not every member kicks every other member, especially if the group is fairly large.

Subsequently, other researchers have argued for distinguishing three (e.g., Bruening (2006)), four (e.g., Beck (2001)) or six readings (e.g. Dalrymple et al. (1998)), and I refer the reader to these studies for the data and arguments on which these diverse counts of readings are based. All agree, however, that Weak Reciprocity is at least a possible interpretation, and Bruening (2006) moreover argues that it is sufficient for most reciprocal sentences with eventive predicates. ${ }^{2}$ I will therefore only derive the weak reading for CQ reciprocal sentences. Future work will have to show whether it is empirically justified to recognize other readings in this language, and how they can be derived compositionally.

\section{The Cuzco Quechua data}

CQ is an agglutinative language which employs a large number of derivational and inflectional verbal suffixes encoding a variety of semantic notions (see Cusihuaman (2001) for an overview). Some of the derivational suffixes are valence changing such as the causative suffix -chi, the benefactive - $p u$, and the reflexive $-k u$. The basic word order in CQ is $(\mathrm{S})(\mathrm{O}) \mathrm{V}$, though this is quite variable. Person suffixes on the verb are sufficient for marking the grammatical relations of subject and object, that is, independent pronouns can be, and often are omitted.

In this section, I will provide the data to be accounted for and describe informally the meanings of the suffixes $-n a$ and $-k u$, which together derive reciprocity. The textual examples in (3) further illustrate the reciprocal construction. ${ }^{3}$

\footnotetext{
${ }^{2}$ Following Fiengo and Lasnik (1972), Bruening (2006) claims that strong reciprocity is only required for stative predicates.

${ }^{3}$ Where not indicated otherwise, examples are elicited, that is, either translated from Spanish or constructed by the author and accepted/confirmed by native speaker consultants. The labels for morphemes used in the glosses are largely based on Cusihuaman's (2001). The main exception is the label PA ('pluractional') for the suffix - $n a$, which is based on my own analysis. Abbreviations used in glosses: 10: first person object, 1s20: first person subject second person object, 1EXCL: first person exclusive, 1INCL: first person inclusive, 3: third person, ABL: ablative, ACC: accusative, ADD: additive, BEN: benefactive, CAUS: causative, CIS: cislocative, COLL: collective, COM: comitative, CONT: continuative, DIM: diminutive, DIR: direct evidence, EMO: emotive, ILLA: illative, DIST: distributive, IMP: imperative, INC: inchoative, INT: intensifier, LIM: limitative, LOC: locative, NEG: negation, NMLZ: nominalizer, NMLZ.SS: same subject nominalizer, NX.PST: non-experienced past, PA: pluractional, PL: plural, PROG: progressive, PRTC: participle, PST: past, REFL: reflexive, TOP: topic.
} 
(3) a. Kunan-qa chay-lla-ta-raq tapu-na-yu-ku-nchik. now-TOP this-LIM-ACC-CONT ask-PA-INT-REFL-1INCL

'For now we only ask each other this.' ("Eso nomás por ahora nos preguntaremos.")

(Vengoa Zúñiga 1998:15)

b. Pay-kuna pura qu-na-ku-sha-n-ku.

(s)he-PL amongst give-PA-REFL-PROG-3-PL

'They are giving each other (things).' (Description of video clip)

c. Qusqu kay-man-qa ham-pu-ra-ni, chicu-cha-y-pa papa-n-wan Cuzco this-ILLA-TOP come-DEF-PST-1 boy-DIM-1-GEN father-3-COM t'aqa-na-ku-spa.

separate-PA-REFL-NMLZ.SS

'I came here to Cuzco after the father of my boy and I separated from each other.'

(conversation)

The agent of the reciprocal event may be encoded by only the person suffixes on the verb (3a), by an overt plural subject NP (3b), or by a (potentially dropped) singular or plural subject NP plus a comitative NP $(3 \mathrm{c}){ }^{4}$

The reciprocal relation may hold between the agent and theme, (3a), or, with a ditransitive verb, between the agent and recipient, $(3 \mathrm{~b}) .{ }^{5}$ In the presence of derivational suffixes that introduce additional arguments such as the causative -chi the reciprocal relationship may also hold between the agent and this additional argument, as shown in (4). ${ }^{6}$

\footnotetext{
${ }^{4}$ In CQ, using the comitative suffix - $(p u)$ wan is a regular strategy of forming conjoined NPs, as shown in (i).

(i) Tayta-y-wan mama-y-puwan-mi llaqta-ta-qa ri-n-ku. father-1-COM mother-1-COM-DIR town-ACC-TOP go-3-PL 'My father and mother have gone to town.' ("Al pueblo fueron mi papá y mi mamá.") (Cusihuaman 2001:140)

In (i), the conjoined subject NP is plural as indicated by the plural agreement on the verb. In (3c), however, the use of the comitative NP does not result in a syntactically plural subject NP. The use of the same subject nominalizer -spa indicates that the subject of the subordinate clause is first person singular, that is, the comitative NP does not seem to form a single NP with the subject here. I thank an anonymous reviewer for pointing this out. The same reviewer suggests that there is a semantic implication of this construction that the singular subject assumes responsibility for the action, so that a more adequate translation might be '. . . after I separated from the father of my boy.' I will leave it to future research to determine the precise semantics of comitative NPs in reciprocal constructions. See Dimitriadis (2004) for a discussion of this strategy from a cross-linguistic perspective.

${ }^{5}$ In CQ, it appears to be impossible to establish a reciprocal relation between the agent and theme of ditransitive verbs or between the theme and recipient. The former is the case for verbal reciprocals in other languages as well, and the latter appears to be impossible in any language (Bruening 2006).

${ }^{6}$ Arguably, (i) and (ii) are examples in which the reciprocal relation holds between the agent and a beneficiary argument introduced by the benefactive suffix $-p u$.

(i) Chay-pis waqa-pu-na-ku-n-ku. this-ADD cry-BEN-PA-REFL-3-PL

'They cried with each other.' ("Lloraron en los brazos el uno del otro")

(Itier 1999:196)
} 
(4) Chay-pi tawa runa-kuna malli-chi-na-ku-sha-n-ku imaymana-ta. this-LOC four person-PL taste-CAUS-PA-REFL-PROG-3-PL whatever-ACC

'There, four people make each other taste different things.'

(Description of video clip)

Further research is required to determine exactly which arguments can participate in reciprocity marked by $-n a-k u,{ }^{7}$ and I will in the following only develop a formal analysis of reciprocity holding between the agent and theme of simple transitive verbs.

While some grammar writers treat -naku as a single suffix, Muysken (1981) showed that it consists of the two suffixes -na and $k u$. One argument for the bipartite analysis is the fact that $-n a$ and $-k u$ can be split by intervening suffixes. For example, in (3a), they are separated by $-y u$. Furthermore, both $-k u$ and - na can occur without the other: $-k u$ on its own marks reflexivity and, as argued below, -na marks pluractionality. In the following two sections, the meaning of these two suffixes will be discussed informally.

\subsection{The meaning of $-n a$}

The suffix - na has a variety of uses. ${ }^{8}$ This section discusses its use as a pluractional marker. As such, it is most productive within the reciprocal construction as illustrated above. When -na precedes the causative suffix - chi (5a), or when

(ii) Asi-pu-na-ku-n-ku pay-kuna pura laugh-BEN-PA-REFL-3-PL (s)he-PL amongst

'They are laughing together/with each other.' (elicited description of a video clip in which two people are laughing) However, it is not clear whether $-p u$ in these examples really is the benefactive suffix -pu. According to Cusihuaman (2001:193), -puna in such examples is a single suffix which is used instead of -na with verbs that express that two things are put in contact with each other or that two people are looking at each other. An argument for considering - $p u$ in this construction the benefactive is the fact that with intransitive verbs its presence appears to be necessary for introducing a second argument. While some speakers accept just -naku by itself with intransitive verbs (Faller to appear, Faller 2005), fieldwork in 2006 has revealed that most do not, and those that do, strongly prefer the forms with $-p u$. More research is necessary to understand this construction properly.

${ }^{7}$ See van de Kerke (1996) for a first analysis of the effect of the relevant suffixes in different Quechua varieties on argument structure, as well as Bruening (2006) for a cross-linguistic study of which arguments can be reciprocalized.

${ }^{8}$ One is nominalizing $-n a$ which is used for different kinds of nominalizations, including the formation of nominalized clauses as for example the second - $n a$ in (7a), but also the derivation of nouns from verbs such as puñu- 'to sleep' $\rightarrow$ puñuna 'bed'. Conversely, -na can verbalize certain types of nouns. With nouns denoting locations, it derives verbs meaning 'to put in that location', for example $k$ 'uchu 'corner' $\rightarrow k$ 'uchuna- 'to put in a corner' (Cusihuaman 2001:184). With nouns that denote sets of often small objects attached to a bigger one, for example feathers or seeds, the resulting verbs means to separate the numerous smaller objects from the big one (Cusihuaman 2001:185). For example phuru 'feather' $\rightarrow$ phuruna- 'to pluck', ruru 'seed' $\rightarrow$ ruruna- 'to deseed'. In Faller (to appear) I had hypothesized that this use might be related to the suffix - na that occurs in the reciprocal construction, possibly providing a way of accounting for the distinctness of coarguments, as these verbs tend to denote separating events, but I have in the mean time come to the conclusion that this cannot be the correct analysis. 
used in a passive participle (5b) (cf. van de Kerke $(1996: 21,151)$ ) it alone can convey reciprocity. ${ }^{9}$
a. Hayt'a-na-chi-rqa-ni.
kick-PA-CAUS-PST-1
'I made them kick each other.'
b. Piña-chi-na-sqa puri-ri-n-ku. anger-CAUS-PA-PRTC walk-INC-3-PL

'They walk being in a state of anger with each other.'

Besides showing that -na can occur on its own, the examples in (5) also raise the possibility that -na itself is a reciprocal marker. In fact, Muysken (1981) calls -na 'the reciprocal.' However, he assumes that $-k u$ is necessary to establish an anaphoric relationship with the subject, that is, to ensure that the participants of the subevents are drawn from the plural individual denoted by the subject. Muysken's 'reciprocal' does therefore not encode all essential components of reciprocity. If - $n a$ were a true reciprocal we would expect it to be able to mark reciprocity on its own in any circumstance. But this is not the case, with the exception of the two environments just mentioned, reciprocity always requires both -na and - $k u$. - na can therefore not be analyzed as a reciprocal marker.

Most previous studies have focussed on the role of - $n a$ as part of the reciprocal construction. However, $-n a$ can also be used to mark plurality of events without implications of reciprocity. I will therefore analyze it as a pluractional marker, a term coined by Newman (1990) in order to distinguish plural agreement markers on verbs (well-known from Indoeuropean languages) from verbal markers that express "a broad range of notions typically including action by more than one individual, temporally iterated action, and spatially scattered action (among others)" (Lasersohn 1995:238). The pluractional analysis of $-n a$ is weaker than the analysis presented in the predecessors of this article, Faller (to appear) and Faller (2005), which had followed van de Kerke's (1996) analysis of Bolivian Quechua -na as marking distributivity over participants, times, or locations. Distributivity involves universal quantification, but pluractionality not necessarily. ${ }^{10}$ Since pluractionality subsumes distributivity as a special instance, the pluractional analysis of $-n a$ can account for the same set of data as the distributive analysis, and moreover predicts that - $n a$ should be possible in situations which do not involve universal quantification.

Van de Kerke presents the following two examples in support of analyzing - $n a$ as marking distributivity and against analyzing it as a reciprocal, both

\footnotetext{
${ }^{9}$ In CQ the sequence -nakuchi is ungrammatical. However, in the Ancash and Huanca and possibly other varieties this is the regular way of expressing the causation of a reciprocal event (Muysken 1981:458),(Cerrón Palomino 1976).

${ }^{10}$ In the descriptive literature, pluractional markers are sometimes called distributive. This is somewhat misleading in comparison with the use of the term 'distributive' in the formal semantics literature, where distributivity is usually taken to entail universal quantification. That distributivity should not be identified with pluractionality has been argued, for example, by Matthewson (2000), who has shown that an apparently distributive element in St'át'imcets is a pluractional marker precisely because it does not entail universal quantification.
} 
observed in naturally spoken Bolivian Quechua. ${ }^{11}$ Note that they both also contain the reflexive $-k u$, demonstrating that this combination does not necessarily express reciprocity in this variety.

(6) a. Pay-kuna runa-ta maqa-na-ku-n-ku.

(s)he-PL man-ACC hit-PA-REFL-3-PL

'They hit the man in turn'

(van de Kerke 1996:149)

b. Pay turril-is-man taqha-na-ku-sqa.

(s)he vessel-PL-ILLA bump-PA-REFL-NX.PST

'He bumped into the vessels.'

(van de Kerke 1996:150)

The verbs of both of these examples normally receive reciprocal interpretations, but in the contexts in which they were uttered, they are better translated in the indicated way. The beating in (6a) involved several men beating on another one with whips without that man reciprocating, and given that the vessels described in (6b) were stationary, a reciprocal interpretation cannot have been intended. Instead (6b) means that he bumped into each of the vessels, or, perhaps weaker, that there were several events of bumping into vessels. Van de Kerke notes that such purely distributive uses of $-n a$ are not very common, and I have not been able to get CQ versions of these examples accepted by my consultants. However, I, too, have been lucky to find some naturally occurring examples in which - na marks plurality of events. These are given in (7). ${ }^{12}$

$$
\begin{aligned}
& \text { a. ... mana-n saru-na-wa-na-nchis-chu ka-sqa-nchis-wan } \\
& \text {... not-DIR step.on-PA-1O-NMLZ-1INCL-NEG be-NMLZ-1INCL-COM } \\
& \text { '... (that) they must not discriminate against us (lit.: 'trample on } \\
& \text { us') for what we are.' ("que no nos discriminen por lo que somos)" }
\end{aligned}
$$

(FARTAC:46)

b. Maskha-na-ri-ku-spa puri-sha-n alqu. search-PA-INC-REFL-NMLZ.SS walk-PROG-3 dog

'The dog walks, searching (for food) all over the place.'

(spontaneous utterance in casual conversation)

Saru- means to step on something, and, according to the consultants who accept (7a), saruna- is best translated as pisotear 'to trample', that is, an action

\footnotetext{
${ }^{11}$ Glosses are the current author's. Van de Kerke glosses - $n a$ as REC 'reciprocal'.

${ }^{12}$ In Faller (to appear) and Faller (2005) I also presented the example in (i) as an illustration of the distributive use of -na:

(i) Asnu-man chaqna-na-y kay kustal-kuna-ta donkey-ILLA load-PA-IMP this sack-PL-ACC

'Load all the sacks onto the donkeys.'

This was judged acceptable by one of my consultants under the interpretation that each sack should be loaded onto the donkey, However, this same consultant does not accept this example anymore under this reading, and there is therefore some doubt that - na can be used to indicate distribution over objects. Another consultant accepts the example under a repeated action interpretation; her comment "amarrarlos a cada rato" 'to tie them up again and again', reinforces the analysis of $-n a$ as a pluractional marker with temporal interpretations.
} 
that involves repeated stepping on something. (The Spanish translation as discriminar 'to discriminate' provided in the publication from which this example is taken, is a rather free translation.) (7a) is a relatively clear case in which -na marks plurality of events, but not necessarily distributivity. That is, there is no sense in which - $n a$ here introduces universal quantification over times. ${ }^{13}$ In contrast, (7b) is interpretable as distribution over locations, though it is also compatible with the weaker notion of plurality of events. ${ }^{14}$ Note that the contribution of $-k u$ in this example is to indicate that the subject is a beneficiary of the described event. This use of $-k u$ will be discussed in the next section.

While such purely pluractional examples of -na occur, they are quite rare. There is also considerable variation between speakers and not everyone consulted accepts the examples in (7) as grammatical. Nevertheless, the existence of these examples indicates that marking plurality of events is at least one possible meaning of $-n a$, and I will argue below that assuming this meaning for $-n a$ is sufficient for deriving reciprocity. ${ }^{15}$ The rarity of the examples calls for an explanation, of course, but it is not within the scope of this paper to fully investigate this. My hypothesis is that $-n a$ is restricted in its use because of the existence of other pluractional markers in the language. For example, the suffix - paya adds the meaning of repeated or repetitive action (wisq'a- 'to close', wisq'a-paya- 'to close again and again') (Cusihuaman 2001:189), and the suffix (y)kacha adds the meaning that the described action is scattered in space (apa'to take', apa-ykacha- 'to take everywhere') or repeated (kumpa-ku- 'to fall', kumpa-kacha-ku- 'to fall again and again') (Cusihuaman 2001:188). ${ }^{16}$ In fact, the example in (7a) becomes acceptable to everyone if $-n a$ is replaced with -paya. There are other verbal suffixes (Cusihuaman 2001) which appear amenable to a pluractional analysis, and the study of the precise semantics of these markers

\footnotetext{
${ }^{13}$ However, as pointed out by an anonymous reviewer, one could also analyze (7a) as involving distribution over the members of the plural object such that each of us is being stepped on (potentially only once). I have not been able to obtain clear judgments on whether this reading is to be preferred over the repeated stepping reading, though it seems to me that this example or any other use of saruna does not entail that each member of the object group is being stepped on. I have also not been able to obtain examples with this or other verbs containing - na that unequivocally involve distributivity over the object group (see also footnote (29)). To really show that we are dealing with pluractionality one would need an example with a singular object. Unfortunately, I have also not been able to obtain examples of this kind. However, the fact that consultants volunteered as a translation of saruna- into Spanish pisotear 'to trample' suggests to me a pluractional interpretation. Moreover, (7b) cannot be analyzed as distribution over the object.

${ }^{14} \mathrm{As}$ an anonymous reviewer has pointed out, $(7 \mathrm{~b})$ could out of context also mean that the dog is engaged in a mutual searching activity with other dogs ('searching for each other'), and this would in fact be the more common interpretation. However, this example was uttered in a context in which there was only one dog and he was searching for food in every corner of the kitchen. In this context, no reciprocal interpretation could have been intended.

${ }^{15}$ Given the relative unproductivity of $-n a$ as a purely pluractional marker, taking this meaning as basic and deriving reciprocity from it is a bit like "turning the world upside down" in the words of an anonymous reviewer. This is true, but leads in my opinion to a simpler analysis than taking the reciprocal meaning as basic and trying to derive the non-reciprocal uses from it.

${ }^{16}$ I would like to thank an anonymous reviewer for drawing my attention to the suffix -(y)kacha and its spatial meaning.
} 
will be an interesting topic for further investigation.

\subsection{The meaning of $-k u$}

The verbal suffix $-k u$ has several functions, the one most relevant for current purposes is the marking of reflexivity illustrated in $(8) .{ }^{17}$

(8) Asnu-n hayt'a-ku-n.

donkey-DIR kick-REFL-3

'The donkey kicks itself.'

A related use of $-k u$ is as a benefactive (cf. van de Kerke (1996:144)), requiring the beneficiary to be coreferential with the subject, as in (9).

(9) Asnu-ta-n ranti-ku-rqa-ni.

donkey-ACC-DIR buy-REFL-PST-1

'I bought myself a donkey.'

Arguably, $-k u$ is still reflexive in this use, indicating that the reflexive relation holds between a benefactive argument and the subject, and it can therefore be considered an extension of its basic reflexive use.

In addition, as is typologically common, $-k u$ also has uses as a middle and anticausative marker (van de Kerke 1996:161).

With the pluractional meaning for $-n a$ and the reflexive meaning of $-k u$ having been given empirical support, we are now in a position to see how the reciprocal interpretation can arise when they are combined. Reciprocity involves plurality of events and this is marked by $-n a$. The function of $-k u$ is to identify the agent and the theme of the sum event, ensuring that the participants of the subevents are drawn from the same group. This alone does not constitute reciprocity yet, but if we can find the other ingredients, universal quantification and distinctness of the participants in the subevents, somewhere else, then the combination of $-n a$ and $-k u$ provides a very good skeleton. In the following section I argue that universal quantification comes for free with plural predication and the notion of plural agents and themes, and that the distinctness condition is in fact a general condition on coarguments of a predicate.

\footnotetext{
${ }^{17}$ Note that this has to be understood as semantic reflexivity in the sense that the two arguments of a transitive verb are coreferential, but the resulting verb still can combine with a syntactic complement. This position can be occupied, for example, by a body part noun, as shown in (i).

(i) Juan uya-n-ta maqli-ku-n. Juan face-3-ACC wash-REFL-3 'Juan washes his face.'

The possessor of the body part noun is restricted to be the subject. Van de Kerke (1996:160) suggests that this is explained if one assumes that in Quechua "body parts are identified by means of the referential index of the subject possessor on the whole NP." Thus, the body part noun is in fact coreferential with the sentence subject.
} 
The account to be developed in the following sections is cast in an neoDavidsonian event semantics. Having events in the representation language and as ontological primitives makes certain aspects in the analysis of reciprocity straightforward. For example, it is easy to distinguish the reciprocal sum event and the subevents of which it is constituted. Event semantics also is usually the framework of choice for work on pluractionality, as again, it captures straightforwardly the idea that a pluractional marker pluralizes events, not objects. ${ }^{18}$

\section{Cumulativity and Reciprocity}

Langendoen (1978) observed that reciprocal sentences are interpreted in a similar fashion to relational plurals. A sentence like (10) is true if (i) each woman released some prisoner, and (ii) each prisoner was released by some woman. This is captured by the semantic representation in (10b), where $\mathrm{A}=$ the set denoted by the women, $\mathrm{B}=$ the set denoted by the prisoners, and $\mathrm{R}=$ the relation denotated by release.

(10) The women released the prisoners. $(\forall x \in A)(\exists y \in B)(x R y) \wedge(\forall w \in B)(\exists z \in A)(z R w)$

(Langendoen 1978:185)

Compare this with the weak interpretation of the reciprocal sentence in (11) (an unpacked version of (2)).

(11) The women released each other.

$$
(\forall x \in A)(\exists y \in A)(x R y \wedge x \neq y) \wedge(\forall w \in A)(\exists z \in A)(z R w \wedge w \neq z)
$$

The two semantic representations differ only minimally. We can see that replacing the second plural NP with the reciprocal pronominal each other has the effect of identifying A and B, and of adding the requirement that the arguments of $\mathrm{R}$ be distinct. This latter requirement is needed to ensure that the reciprocal sentence is not verified by a situation in which some women only release themselves. It is a plausible hypothesis then that the shared semantics should be accounted for in a parallel fashion. Such accounts have since been worked out in detail by Sternefeld (1998) and Beck (2001), who both have developed theories of plurality that treat reciprocal sentences as special instances of relational plurals. The interpretation of reciprocal and relational plural sentences is derived by cumulating the relevant relation; the reciprocal each other only contributes the non-identity condition and the anaphoric link between the two NPs.

In the first instance, cumulativity is a property of predicates $P$ (Krikfa 1982, Link 1998). ${ }^{19}$ A predicate $P$ is cumulative if it is closed under the sum operation.

\footnotetext{
${ }^{18}$ Note that the analysis of pluractionality does not require events as ontological primitives, as is shown, e.g., by Van Geenhoven's (2004,2005) successful analysis of pluractionality in West Greenlandic.

${ }^{19}$ I assume an ontology along the lines of Link (1998), where the domain of individuals $D_{e}$ contains atomic/singular individuals as well as plural individuals. $D_{e}$ is closed under the sum
} 
Plural nouns are cumulative. E.g., if Fido and Buddy are dogs and Rover and Sam are dogs, then Fido, Buddy, Rover, and Sam are dogs. Singular nouns are not cumulative: if Fido is a $d o g$ and Buddy is a $d o g$, it does not follow that Fido and Buddy is a dog (they are dogs). Link's definition of the plural '*' operator in (12) (as cited in Sternefeld (1998:304)) directly captures cumulativity.

(12) For any set $P, * P$ is the smallest set such that

a. $P \subseteq * P$, and

b. if $a \in * P$ and $b \in * P$, then $a \oplus b \in * P$

For example, if $\mathbf{d}^{\prime} \mathbf{g}^{\prime}=\{$ fido, rover, buddy $\}$, then $* \mathbf{d o g}^{\prime}=\{$ fido, rover, buddy, fido $\oplus$ rover, fido $\oplus$ buddy, rover $\oplus$ buddy, fido $\oplus$ rover $\oplus$ buddy $\}$. Note that $* \mathrm{P}$ contains atomic individuals, that is, a starred predicate is true of single individuals as well. To derive a plural proper denotation, the atoms have to be subtracted from $*$ P. Rullmann and You (2003) argue that Mandarin Chinese unmodified nouns have "general number", a term coined by Corbett (2000), that is, they are $* \mathrm{P}$ predicates. In this language, an optional plural marker $\mathrm{PL}$, the semantics of which is given in (13), can be used to derive a properly plural interpretation. As will be shown below, CQ is like Mandarin in this respect.

(13) $\mathrm{PL}(\mathrm{N})=* \mathrm{~N}-\mathrm{At}$

(Rullmann and You 2003)

In Sternefeld's and Beck's theories, relational plural sentences involve cumulation of a relation, which is achieved by defining a two-place operator ' $* *$ ' which pluralizes the arguments of a relation simultaneously. (14) is based on Sternefeld's (p. 304) definition of '**', differing from it only in adding an event argument.

(14) For any $R$ relating an event argument and two individual arguments, let $* * R$ be the smallest relation such that

a. $R \subseteq * * R$, and

b. if $\left\langle a, b, e_{1}>\in * * R\right.$ and $<c, d, e_{2}>\in * * R$, then $<a \oplus c, b \oplus d, e_{1} \oplus e_{2},>\in * * R$

(15b) illustrates cumulation of the verb kick with the extension in (15a). (Please note that the representations for extensions do not directly correspond to the neo-Davidsionian semantic representations to be developed below, see footnote 20)..$^{20}$ )

operation: if $a$ and $b$ are individuals in $D_{e}$, then $a \oplus b$ is an individual in $D_{e}$. Sums and their constituent parts form a join semi-lattice, structured by the ordering relation $\leq$. Thus, $a \leq a \oplus b$. The ontology also contains events as primitive objects, and the domain of events $D_{s}$ is structured in the same way as $D_{e}$.

${ }^{20}$ For simplicity, I present the extensions of transitive verbs as triples, consisting of $<$ agent,theme,event $>$. In the semantic representations to be developed below, I will use neo-Davidsonian thematic role functions on events, e.g. kick translates as $\lambda x . \lambda y \cdot \lambda e \cdot \mathbf{k i c k}^{\prime}(e)$ $\wedge \mathrm{AG}(e)=x \wedge \mathrm{TH}(e)=y$. In such a framework the extension of a verb only contains events, e.g. $\mathbf{k i c k}^{\prime}=\left\{e_{1}, e_{2}, e_{3}\right\}$. The extensions in (15) should therefore be considered a combination of the extension of $\mathbf{k i c k}^{\prime}$ and the extensions of the thematic roles AGENT $\left.\left(\left\{<a, e_{1}>,<c, e_{2}>,<f, e_{3}\right\rangle\right\}\right)$ and Theme $\left(\left\{<b, e_{1}>,<d, e_{2}>,<g, e_{3}>\right\}\right)$. 


$$
\begin{aligned}
& \text { a. } \mathbf{k i c k}^{\prime}=\left\{<a, b, e_{1}>,<c, d, e_{2}>,<f, g, e_{3}>\right\} \\
& \text { b. } * * \mathbf{k i c k}^{\prime}=\left\{<a, b, e_{1}>,<c, d, e_{2}>,<f, g, e_{3}>,\right. \\
& \quad<a \oplus c, b \oplus d, e_{1} \oplus e_{2}>,<c \oplus f, d \oplus g, e_{2} \oplus e_{3}>, \\
& \left.\quad<a \oplus f, b \oplus g, e_{1} \oplus e_{3}>,<a \oplus c \oplus f, b \oplus d \oplus g, e_{1} \oplus e_{2} \oplus e_{3}>\right\}
\end{aligned}
$$

Thus, a sentence like The donkeys kicked the dogs is true iff an ordered triple consisting of the sum denoted by the donkeys, the sum denoted by the dogs, and a sum of events, is in the denotation of $* * \mathbf{k i c k}^{\prime}$. This is equivalent to the truth conditions for relational plural sentences given in (11) (Sternefeld 1998, Beck 2001). Saying that such a triple is in the extension of $* * \mathbf{k i c k}^{\prime}$ amounts to saying that the donkey sum-individual is a plural agent $* \mathrm{AG}$ in a plural event of kicking dogs, and that the dog sum-individual is a plural theme $* \mathrm{TH}$ in a plural event of being kicked by donkeys (see Landman (2000) for a detailed discussion of plural thematic roles). Being a plural agent $* \mathrm{AG}$ in a plural event of kicking dogs requires every part of the donkey sum individual to be an agent in a subevent, that is, every donkey has to kick some dog. Likewise, being a plural theme $*$ TH requires every part of the dog sum individual to be a theme in a subevent, that is, every single dog has to be kicked by some donkey. Therefore, the following equivalence holds between the plural predicate $* * \mathbf{k i c k}^{\prime}$ and its atomic counterpart $\mathbf{k i c k}^{\prime}$ ( $a=$ sum individual denoted by the donkeys, $b=$ sum individual denoted by the dogs $).{ }^{21}$

(16) $\exists e . * * \operatorname{kick}^{\prime}(e) \wedge * \operatorname{AG}(e)=a \wedge * \operatorname{TH}(e)=b \Leftrightarrow$

$$
\begin{aligned}
& \exists e\left[\forall x \leq_{\mathrm{AT}} a . \exists y \leq b . \exists e^{\prime} \leq e\left[\mathbf{k i c k}^{\prime}\left(e^{\prime}\right) \wedge \mathrm{AG}\left(e^{\prime}\right)=x \wedge \mathrm{TH}\left(e^{\prime}\right)=y\right]\right. \\
& \left.\wedge \forall y \leq_{\mathrm{AT}} b . \exists x \leq a \cdot \exists e^{\prime} \leq e\left[\operatorname{kick}^{\prime}\left(e^{\prime}\right) \wedge \mathrm{AG}\left(e^{\prime}\right)=x \wedge \mathrm{TH}\left(e^{\prime}\right)=y\right]\right]
\end{aligned}
$$

Thus, plural verbs inherently come with the $\forall \exists$ quantifier sequence needed for weak reciprocity (Beck 2001). To derive the reciprocal interpretation of, for example, The donkeys kick each other we only have to add the distinctness condition and let $a=b$, as in (17).

(17) $\exists e . * * \operatorname{kick}^{\prime}(e) \wedge * \operatorname{AG}(e)=a \wedge * \operatorname{TH}(e)=a \Leftrightarrow$

$\exists e\left[\forall x \leq_{\mathrm{AT}} a . \exists y \leq a . \exists e^{\prime} \leq e\left[\operatorname{kick}^{\prime}\left(e^{\prime}\right) \wedge \mathrm{AG}\left(e^{\prime}\right)=x \wedge \mathrm{TH}\left(e^{\prime}\right)=y \wedge x \neq y\right]\right.$

$\left.\wedge \forall y \leq_{\mathrm{AT}} a . \exists x \leq a . \exists e^{\prime} \leq e\left[\mathbf{k i c k}^{\prime}\left(e^{\prime}\right) \wedge \mathrm{AG}\left(e^{\prime}\right)=x \wedge \mathrm{TH}\left(e^{\prime}\right)=y \wedge x \neq y\right]\right]$

Now these equivalences hold as long as we do not deal with situations in which individuals act collectively. For example, the sentence The children ate the

\footnotetext{
${ }^{21} \operatorname{Read} x \leq_{\mathrm{AT}} y$ as " $x$ is an atomic part of $y$ ". Universal quantification in (16) is restricted to atomic individuals because it is not the case that all properly plural individuals are participants of an atomic kicking event. However, the equivalence in (i) holds for all parts of $a$ and $b$.

(i) $\exists e . * * \operatorname{kick}^{\prime}(e) \wedge * \mathrm{AG}(e)=a \wedge * \mathrm{TH}(e)=b \Leftrightarrow$$$
\exists e\left[\forall x \leq a . \exists y \leq b . \exists e^{\prime} \leq e\left[* * \operatorname{kick}^{\prime}\left(e^{\prime}\right) \wedge * \mathrm{AG}\left(e^{\prime}\right)=x \wedge * \mathrm{TH}\left(e^{\prime}\right)=y\right] \wedge\right.
$$$$
\left.\forall y \leq b . \exists x \leq a . \exists e^{\prime} \leq e\left[* * \mathbf{k i c k}^{\prime}\left(e^{\prime}\right) \wedge * \mathrm{AG}\left(e^{\prime}\right)=x \wedge * \operatorname{TH}\left(e^{\prime}\right)=y\right]\right]
$$

Since we are ultimately interested in how the atomic elements of a plural individual relate to the atomic subevents of a plural event, I prefer to state the equivalence as in (16). Note that the problems with collective action discussed for (16) in the following also hold for (i), as the reader can confirm for her-/himself.
} 
pizzas is true if not every child ate an entire pizza. All that is required is that each child ate at least part of a pizza and that together they finished the pizzas (Kratzer to appear). Similarly, imagine a situation in which two boxes, $b_{1}$ and $b_{2}$, have to be carried upstairs, and there are two children to do this, Isabel, $i$, and Pablo, $p$. Isabel carries one box by herself, but the second one is so heavy that it requires both Isabel and Pablo to carry it. The extensions of carry' and $* *$ carry $^{\prime}$ are then as in $(18) .^{22}$

$$
\begin{aligned}
& \text { a. } \text { carry }^{\prime}=\left\{<i, b_{1}, e_{1}>,<i \oplus p, b_{2}, e_{2}>\right\} \\
& \text { b. } * * \text { carry }^{\prime}=\left\{<i, b_{1}, e_{1}>,<i \oplus p, b_{2}, e_{2}><i \oplus p, b_{1} \oplus b_{2}, e_{1} \oplus e_{2}>\right\}
\end{aligned}
$$

In this situation the sentence Isabel and Pablo carried the boxes upstairs and its semantic representation $\exists e . * * \operatorname{carry}^{\prime}(e) \wedge * \mathrm{AG}(e)=i \oplus p \wedge * \mathrm{TH}(e)=b_{1} \oplus b_{2}$ are true, because $i \oplus p$ is a plural agent and $b_{1} \oplus b_{2}$ a plural theme in the plural carrying event $e_{1} \oplus e_{2}$. But it is not true that for every part $x$ of $i \oplus p$ there is a part $y$ of $b_{1} \oplus b_{2}$ such that $x$ carried $y$ upstairs, because $p$ did not carry a box by himself. The equivalence in (16) is therefore too strong for the general case. For collective action all that is required is that every part of the plural agent (and theme) is part of a sum (minimally consisting of itself, maximally of the plural agent (theme) as a whole) which is an agent (theme) in a subevent. This is captured in the following reformulation of (16) for any relation $R$ in terms of "possible intermediate individuals" ( $x^{\prime}$ and $y^{\prime}$ in (19); for simplicity, I continue to use the constants $a$ and $b$ for the agent and theme), ${ }^{23}$ a notion adopted from Langendoen and Magloire's (2003) reflexivity criterion to be discussed in section 4.2 .

$$
\text { (19) } \begin{aligned}
\exists e . * * \mathbf{R}(e) \wedge * \mathrm{AG}(e)=a \wedge * \mathrm{TH}(e)=b \Leftrightarrow \\
\exists e\left[\forall x \leq \leq_{\mathrm{AT}} a \cdot \exists x^{\prime} \leq a \cdot \exists y \leq b . \exists e^{\prime} \leq e\left[x \leq x^{\prime} \wedge\right.\right. \\
\left.\quad \mathbf{R}\left(e^{\prime}\right) \wedge \mathrm{AG}\left(e^{\prime}\right)=x^{\prime} \wedge \mathrm{TH}\left(e^{\prime}\right)=y\right] \wedge \\
\forall y \leq \leq_{\mathrm{AT}} b . \exists y^{\prime} \leq b . \exists x \leq a \cdot \exists e^{\prime} \leq e\left[y \leq y^{\prime} \wedge\right. \\
\left.\quad \mathbf{R}\left(e^{\prime}\right) \wedge \mathrm{AG}\left(e^{\prime}\right)=x \wedge \mathrm{TH}\left(e^{\prime}\right)=y^{\prime}\right]
\end{aligned}
$$

In addition to cumulative readings, English sentences with two plural or quantified NPs can also have readings in which one NP is distributed over the other. Take, for example, the sentence Five donkeys kicked ten dogs. In the reading in which five donkeys has wide scope, each donkey kicked ten dogs, which are not necessarily the same ten dogs for each donkey, that is, there might be up to 50 dogs involved. When ten dogs has wide scope, the resulting reading is that each

\footnotetext{
${ }^{22}$ Note that unstarred verbal predicates may contain plural individuals as agents or themes. For example, in (18a) the agent of $e_{2}$ is $i \oplus p$. However, they may not contain plural events, that is, cumulation of verbal predicates in a neo-Davidsonian approach turns on events. This gives us an immediate handle on collective action. Any plural agent or theme of an atomic event is necessarily a collective agent or theme. In contrast, a plural participant of a plural event is not necessarily a collective participant. Thus, $a \oplus c$ in (15b) is not a collective agent because there is no triple in (15a) which has $a \oplus c$ as an agent (cf. Kratzer (to appear)).

${ }^{23}$ These intermediate individuals are comparable to the subsets of the cover of a plural individual. For covers see, for example, the work by Schwarzschild (1996), Landman (2000) or Beck (2001).
} 
dog was kicked by five donkeys, which are again not necessarily the same five donkeys for each dog. That is, while the cumulative reading of Five donkeys kicked ten dogs entails that there are a total of five donkeys and a total of ten dogs, the two scoped distributive readings allow for more animals.

It is often assumed that the scope mechanism is optional and freely available in the syntax without requiring overt expression, at least for English. Similarly, the plurality operators $*$ and $* *$ are often assumed to be freely available syntactic operators (Sternefeld 1998, Beck 2001). This explains why a sentence like Five donkeys kicked ten dogs without any further context is ambiguous between a cumulative and two distributive readings. An alternative view assumes that the denotations of lexical roots are cumulative from the start, that is, their cumulativity is not derived from a non-cumulative version by applying silent star operators in the syntax. This view has recently been defended for English verbs by Kratzer (to appear), following suggestions by Krifka (1992) and Landman (1996). The most obvious and immediate advantage of assuming that verbs have a cumulative denotation is that it provides an immediate account of "the effortless availability of a cumulative interpretation" (Kratzer to appear) for sentences with two plural NPs without having to postulate phonologically silent $*$ and $* *$ operators. I will adopt this lexical view of cumulativity for CQ predicates, both nouns and verbs. For example, kick translates as $* * \mathbf{k i c k}^{\prime}$, not just kick' $^{\prime 24}$

However, the assumption that predicates are lexically cumulative predicates cannot derive the two scoped distributive readings and Kratzer (to appear) therefore assumes a second kind of cumulativity, phrasal cumulativity. In languages like English, the scoped distributive readings require the presence of plural DPs, and she therefore argues that phrasal cumulativity is the result of these DPs introducing *-operators which may pluralize their sister Verb Phrases. Not all languages introduce phrasal cumulativity via nominal plural markers, however. Kratzer mentions Chinese, where the scopal distributive readings requires an overt distributivity marker. This is also the case for CQ, as discussed in the next section, (22).

\section{Composing reciprocity in Cuzco Quechua}

For CQ, the assumption that all predicates and relations are lexically cumulative makes immediate sense. Like Mandarin Chinese (Rullmann and You 2003), CQ nouns have general number. For example, the Spanish translation provided for (20a) translates uwiha as ovejas 'sheep (pl)', but a singular interpretation would out of context also be possible.

a. Uwiha-q qhepa-n-ta urqo-ta ri-spa-n, $\ldots$ sheep-GEN behind-3-ACC mountain-ACC go-NMLZ.SS-DIR

'Walking behind the sheep (pl.) to the mountains ...' ("Yendo a los

${ }^{24}$ Unstarred predicates are nevertheless available in the semantic representation language, and I will use them in semantic representations to state entailments of starred predicates. 
cerros tras las ovejas")

(Valderrama Fernandez and Escalante Gutierrez 1982:26)

b. Urqo-pi hina uwiha-cha-kuna michi-mu-sqa-y-man hina ... mountain-LOC like sheep-DIM-PL herd-CIS-NMLZ-1-ILLA like

'As I was herding the sheep in the mountains ...' ("En lo que pasteaba a las ovejitas en los cerros" ...)

(Valderrama Fernandez and Escalante Gutierrez 1982:26)

If nouns have a cumulative denotation to begin with, then the data in (20a) is expected; no zero-derivation or the application of a freely available plural operator is necessary to account for the plural interpretation, as would be on an account in which nouns denote sets of atoms. There is an optional nominal plural suffix, -kuna, which enforces a plural interpretation of nouns, as for example in (20b), which only has an interpretation with two or more sheep. -kuna can therefore be analyzed as instantiating Rullmann and You's (2003) PL operator in (13).

Verbs, too, can denote both singular and plural events without requiring any overt (agreement) morphology to indicate either. Thus, tarpachikun, which is morphologically unmarked for number, denotes several catching events in (21a), but only a single one in (21b).

a. Chay-pi-ya suwa-kuna tarpa-chi-ku-n.

this-LOC-EMO thief-PL catch-CAUS-REFL-3

'In this, the thieves let themselves be caught.' ("Es en eso pues que los ladrones se hacen atrapar.")

(Espinoza 1997:82)

b. Chay-pi-ya Tashi tarpa-chi-ku-n.

this-LOC-Emo Tashi catch-CAUS-REFL-3

'In this, Tashi let himself be caught.'

Again, if verbs are lexically cumulative, this is immediately accounted for. While these data do not in and of themselves prove that lexical roots have cumulative denotations (the alternative being the silent application of pluralization operators), making this assumption leads to a simpler analysis.

In contrast to English, the distributive readings which require the application of a scope mechanism are only available in CQ if an overt distributive marker is used. For example, (22a) can only mean that there is a total of five donkeys and a total of 10 dogs. ${ }^{25}$ As shown in (22b), a distributive interpretation requires overt marking, such as the suffix $-n k a$ which attaches to the distributive share (Faller 2001).

\footnotetext{
${ }^{25}$ This claim is based on my own fieldwork. Fellow Quechua linguist Rachel Hastings, however, has obtained interpretations for similar sentences which involve the object NP being distributed over the subject NP. Nevertheless, she also observed that the use of - nka is strongly preferred to express distributive meanings (p.c.). In contrast to sentences with plural NPs, sentences with quantified NPs are expected to exhibit scope ambiguities. Since NPs with numerals appear to be non-scopal, I hypothesize that numerals are non-quantificational.
} 
a. Pisqa asnu chunka alqu-ta hayt'a-rqa-n. five donkey ten dog-ACC kick-PST-3

'Five donkeys kicked ten dogs.'

b. Pisqa asnu chunka alqu-nka-(ta) hayt'a-rqa-n. five donkey ten dog-DIST-ACC kick-PST-3

'Five donkeys kicked ten dogs each.'

The fact that the distributive, but not the cumulative readings require overt marking lends support to the hypothesis that cumulativity is built into lexical predicates, and this is what I will assume for CQ in the following. With this as background, we can now develop a formal semantic account of reciprocity.

\subsection{Pluractionality}

In the previous section we have seen that for nominal predicates in CQ there exists a plural morpheme which forces a plural interpretation of nouns which otherwise allow for both singular and plural reference. Under the assumption that the denotations of verbal predicates also contain both singular and plural events, pluractional markers have the same function, that is, they apply to a verb and return only the set of plural events. But pluractional markers do more than pluralize the verb. They specify the way in which the atomic subevents of a plural event are distinguished from each other, and may require "separate running spaces, running times, or participants" (Lasersohn 1995:251). To capture this, Lasersohn analyzes pluractional markers as introducing the non-overlap condition $\neg\left[f\left(e^{\prime}\right) \circ f\left(e^{\prime \prime}\right)\right]$ into the semantic representation, where $e^{\prime}$ and $e^{\prime \prime}$ are (atomic) subevents, and $f$ is a function that may be instantiated in different ways by different markers. $f$ may be the temporal trace function, resulting in a repetitive or repeated action interpretation, or $f$ may be the spatial trace function, resulting in the interpretation that the action is scattered in space. ${ }^{26}$ $f$ may also refer to the thematic roles of an event, for example, if $f$ is instantiated to THEME the resulting interpretation is that the action is performed on multiple themes. With atomic participants, the non-overlap requirement simply amounts to distinctness. ${ }^{27}$ A pluractional marker may also leave the nature of $f$

\footnotetext{
${ }^{26}$ See, for example, Krifka (1998), Link (1998) on the notion of trace functions. Following Link (1998:201), I assume that times and locations form semilattices, just like events. The temporal and spatial trace functions are partial function from the domain of events to the domain of times and locations respectively. Lasersohn (1995:223) provides a set theoretic definition of the overlap relation. The lattice-theoretic counterpart is given in (i) for two elements $s$ and $t$.
}

(i) $s \circ t \leftrightarrow \exists x[x \leq s \wedge x \leq t]$

(Link 1998:156)

${ }^{27}$ With non-atomic participants, non-overlap is more restrictive than distinctness. For example, the two sum individuals $a \oplus b$ and $a \oplus c$ are distinct, but they overlap. It is not clear to me at this point whether requiring non-overlap of participants may perhaps be too restrictive. But since non-overlap is required for temporal and spatial $f$ (Lasersohn 1995), I will continue to use $\circ$ for $f$ instantiated to thematic roles in order to maintain the generality of the definition. 
unspecified. The semantics of a general pluractional marker can be represented as in $(23) .^{28}$

(23) $\mathrm{PA}=\mathrm{PA}_{v i} \vee \mathrm{PA}_{v t}$

$$
\begin{aligned}
\mathrm{PA}_{v i}: & \lambda P \cdot \lambda x \cdot \lambda e[\neg \mathrm{AT}(e) \wedge P(x)(e) \\
& \left.\wedge \forall e^{\prime}, e^{\prime \prime} \leq_{P} e\left[e^{\prime} \neq e^{\prime \prime} \rightarrow \neg\left[f\left(e^{\prime}\right) \circ f\left(e^{\prime \prime}\right)\right]\right]\right] \\
\mathrm{PA}_{v t}: \quad \lambda R \cdot \lambda x \cdot \lambda y \cdot \lambda e[\neg \mathrm{AT}(e) \wedge R(x)(y)(e) & \\
& \left.\wedge \forall e^{\prime}, e^{\prime \prime} \leq_{R} e\left[e^{\prime} \neq e^{\prime \prime} \rightarrow \neg\left[f\left(e^{\prime}\right) \circ f\left(e^{\prime \prime}\right)\right]\right]\right]
\end{aligned}
$$

CQ - na denotes PA without setting $f$ to a specific value. ${ }^{29}$ This means that depending on how $f$ is chosen, distinct interpretations arise. When $f$ is set to the temporal trace function, a repeated or repetitive action interpretation is derived as in (7a) with saru-na 'to trample', when it is set to the spatial trace function, a scattered in space interpretation is derived as in $(7 \mathrm{~b})$ with maskha-na 'to search all over'. For deriving the reciprocal interpretation, we have to require that the subevents have distinct agent/theme pairs, that is, $f=<\mathrm{AG}, \mathrm{TH}>.^{30}$ To see why it is not enough to require just their agents or themes to be distinct, take the following situation involving the individuals $a$,

${ }^{28}$ The definition in (23) departs from Lasersohn's (1995:256) original definition given in (i) in three ways.

(i) $\operatorname{V-PA}(X) \Leftrightarrow \forall e, e^{\prime} \in X\left[P(e) \& \neg\left[f(e) \circ f\left(e^{\prime}\right)\right]\right] \& \operatorname{card}(X) \geq n$

Lasersohn (1995:256)

First, as pointed out to me by Philippe Schlenker (p.c.), the biconditional in (i) will never be true, because the non-overlap condition $\neg\left[f(e) \circ f\left(e^{\prime}\right)\right]$ is false whenever $e=e^{\prime}$. The condition $e^{\prime} \neq e^{\prime \prime}$ has therefore been added in (23). Second, for simplicity's sake, (23) only requires $e$ to be non-atomic, without requiring there to be a (pragmatically determined) number $n$ of subevents. Third, Lasersohn's definition contains the free variable $P$ ranging over properties of the atomic subevents. $P$ may be different from $V$ to allow for subevents that do not fit the verb's description. This is needed in particular for repetitive event types such as nibbling, where the constituent atomic events are not nibbling events but biting events. However, by making this allowance, we open the door wide for all kinds of subevents. For example, at some level of a kicking event we find an event of a leg moving without that movement counting as a kicking. This event would however not involve a theme, and we would therefore not only have to allow subevents to differ from their superevent in $P$ but also in their argument structure. Since these kinds of complications are not directly relevant to the purposes of this paper, I will simplify matters, and restrict the type of subevents to which the non-overlap condition applies to those events which have the property denoted by the verb. To do this, I introduce the notation $e^{\prime} \leq_{P} e$ as a shorthand for $\exists x^{\prime} \leq x\left[P(x)\left(e^{\prime}\right)\right]$ which would have to be added as a further condition on $e^{\prime}$ and $e^{\prime \prime}$. That is, the second line in the definition of $\mathrm{PA}_{v i}$ would have to be: $\forall e^{\prime}, e^{\prime \prime} \leq e\left[e^{\prime} \neq e^{\prime \prime} \wedge \exists x^{\prime}, x^{\prime \prime} \leq x\left[P\left(x^{\prime}\right)\left(e^{\prime}\right) \wedge P\left(x^{\prime \prime}\right)\left(e^{\prime \prime}\right)\right] \rightarrow \neg\left[f\left(e^{\prime}\right) \circ f\left(e^{\prime \prime}\right)\right]\right]$, and similarly for $\mathrm{PA}_{v t}$.

${ }^{29}$ While this semantics for $-n a$ allows the right kinds of interpretations to be derived, that is, it allows for the temporal and spatial interpretation of saruna and mashkana respectively as well as for the plurality of events in reciprocal sentences, it also overgenerates considerably. For example, saruna is predicted to be also adequately describing a situation in which one agent steps once on a number of different entities, but this is to my knowledge not possible. My hypothesis is that this overgenerative semantics of $-n a$ is reigned in by the existence of more specific morphemes such as -paya and -(y)kacha mentioned at the end of section 2.1.

${ }^{30}$ The overlap relation for pairs of elements may be defined as in (i).

(i) $<s, t>\circ<u, v>\leftrightarrow \exists x \exists y[x \leq s \wedge x \leq u \wedge y \leq t \wedge y \leq v]$ 
$b$, and $c$ and four events: $e_{1}: a$ kicks $b, e_{2}: b$ kicks $a, e_{3}: a$ kicks $c, e_{4}: c$ kicks $b$. This situation satisfies weak reciprocity, but $e_{1}$ and $e_{3}$ have the same agent and $e_{1}$ and $e_{4}$ have the same theme. None of the events have the same agent/theme pair, however. I assume that $<\mathrm{AG}, \mathrm{TH}>(e)=\left\langle\mathrm{AG}(e), \mathrm{TH}(e)>.^{31}\right.$ Together with the distinctness condition requiring the agent and theme of each subevent to be distinct, which will be discussed in section 4.3 , this correctly captures weakly reciprocal situations. As an example, the semantic representation resulting from adding - na to the verb hayt' $a$ 'kick' with $f$ set to distinct agent/theme pairs is shown in (24).

$$
\begin{aligned}
& \text { a. hayt' } a \Rightarrow \lambda x \cdot \lambda y \cdot \lambda e\left[* * \operatorname{kick}^{\prime}(e) \wedge * \operatorname{AG}(e)=x \wedge * \mathrm{TH}(e)=y\right] \\
& \text { b. hayt'a-na } \Rightarrow \\
& \lambda x \cdot \lambda y \cdot \lambda e\left[\neg \mathrm{AT}(e) \wedge * * \mathbf{k i c k}^{\prime}(e) \wedge * \mathrm{AG}(e)=x \wedge * \mathrm{TH}(e)=y \wedge\right. \\
& \left.\forall e^{\prime}, e^{\prime \prime} \leq_{K} e\left[e^{\prime} \neq e^{\prime \prime} \rightarrow \neg\left[<\mathrm{AG}\left(e^{\prime}\right), \operatorname{TH}\left(e^{\prime}\right)>\circ<\mathrm{AG}\left(e^{\prime \prime}\right), \operatorname{TH}\left(e^{\prime \prime}\right)>\right]\right]\right]
\end{aligned}
$$

Assuming the extension of $* * \mathbf{k i c k}^{\prime}$ in $(25 \mathrm{a})$, the extension of $\mathrm{PA}\left(* * \mathbf{k i c k}^{\prime}\right)$ is as in $(25 \mathrm{~b})$

$$
\begin{aligned}
& \text { a. } \left.* * \mathbf{k i c k}^{\prime}=\left\{<a, b, e_{1}\right\rangle,<b, a, e_{2}>,<a \oplus b, a \oplus b, e_{1} \oplus e_{2}>\right\} \\
& \text { b. } \operatorname{PA}\left(* * \mathbf{k i c k}^{\prime}\right)=\left\{<a \oplus b, a \oplus b, e_{1} \oplus e_{2}>\right\}
\end{aligned}
$$

In summary, the effect of the first ingredient of reciprocity in CQ, pluractionality, is to restrict the interpretation of a lexically cumulative verb to a strictly plural interpretation, requiring the subevents of the plural events to be distinct along a dimension $f$. For reciprocity, $f$ must be agent/theme pairs. The next section discusses the second ingredient, reflexivity.

\subsection{Reflexivity}

Reflexivization through marking on the verb usually involves an operation on the verb's argument structure (Reinhart and Reuland 1993), coindexing two (or more) of its arguments. ${ }^{32}$ That reflexivization is an operation on argument structure also in the case of the Quechua verbal reflexive marker - $k u$ has been argued by van de Kerke (1996), and I will adopt this analysis in this general

\footnotetext{
${ }^{31}$ Note that the condition $\neg\left[<\operatorname{AG}\left(e^{\prime}\right), \mathrm{TH}\left(e^{\prime}\right)>0<\operatorname{AG}\left(e^{\prime \prime}\right), \mathrm{TH}\left(e^{\prime \prime}\right)>\right]$ does not make reciprocal sentences false in situations in which an agent acts on a theme more than once. Consider the same situation with the additional event: $e_{5}: a$ kicks $b$. In this situation, it is still true that there is a reciprocal sum event that fulfils the condition that the agent/theme pairs of all its subevents are distinct, namely $e_{1} \oplus e_{2} \oplus e_{3} \oplus e_{4}$, that is, the sentence $A, b$, and c are kicking each other comes out as true, $e_{5}$ is simply irrelevant. It may however seem somewhat odd that according to this analysis the event $e_{1} \oplus e_{2} \oplus e_{3} \oplus e_{4} \oplus e_{5}$ does not qualify as a reciprocal event. However, from a formal perspective, deeming $e_{6}$ as irrelevant for determining the truth conditions is no different from deeming $e_{6}^{\prime}$ : $a$ kisses $b$ as irrelevant.

${ }^{32}$ An exception is Chichewa. Mchombo (1993) argued that its verbal reflexive marker is an incorporated pronominal, and as such a syntactic object of the verb and subject to syntactic binding principles. The Chichewa verbal reciprocal marker, in contrast, is a morpholexical element that operates on the verb's argument structure, and is not subject to syntactic binding principles.
} 
formulation here. In a recent paper, however, Langendoen and Magloire (2003) have argued that a more fine-grained formulation is needed of what it is that is being coindexed. For some relations with a plural antecedent reflexivity necessarily holds at the level of atomic individuals making up the plural individual, but for others this is not the case. An example of the former is the relation be in love with: Anna and Bob are in love with themselves entails Anna is in love with herself and Bob is in love with himself. In contrast, the relation defend does not entail reflexivity on the atomic level: The sentence Anna and Bob are defending themselves can have the interpretation that they collectively defended themselves as a group, in addition to the interpretation Anna defended herself and Bob defended himself, that is, reflexivity may only hold at the level of the plural individual. To capture this, Langendoen and Magloire (2003:48) postulate the so-called reflexivity criterion, which I will adopt as the semantics for CQ - ku. (26) is a neo-Davidsonian event semantic reformulation of the criterion.

(26) $-k u \Rightarrow \lambda R . \lambda x \cdot \lambda e \cdot \forall x_{i} \leq_{\mathrm{AT}} x . \exists z \leq x . \exists e_{z} \leq e\left[x_{i} \leq z \wedge R(z)(z)\left(e_{z}\right)\right]$

The reflexivity criterion is stated in terms of "possibly intermediate individuals" (p. 48) of a plural individual, $z$ in (26), that is, the reflexive relation does not necessarily hold for atoms nor necessarily for the plural individual itself, though it allows for both these options. It is however required that for each atom there exists such an intermediate individual, that is, indirectly, each atom is a participant in the reflexive relation. That intermediate individuals are needed can be seen by enlarging the group as in Anna and Bob and Cedric and Doris defended themselves. This sentence is true in a situation in which Anna and Bob collectively defended themselves and Cedric and Doris collectively defended themselves.

For the analysis of $\mathrm{CQ}$ reciprocity, the reflexivity criterion is necessary to capture the fact that reflexivity holds at the level of the plural individual denoted by the subject, but crucially not at the atomic level, where, as mentioned above, distinctness is required. (27) is the representation for the CQ equivalent of 'They kick themselves' using the semantics of $-k u$ in (26).

$$
\begin{aligned}
& \text { a. Hayt'a-ku-n-ku. } \\
& \text { kick-REFL-3-PL } \\
& \text { 'They kick themselves.' } \\
& \text { b. } \exists e . \forall x_{i} \leq_{\mathrm{AT}} \text { they'. } \exists z \leq \text { they'}^{\prime} . \exists e_{z} \leq e\left[x_{i} \leq z \wedge\right. \\
& \left.\quad * * \operatorname{kick}^{\prime}\left(e_{z}\right) \wedge * \operatorname{AG}\left(e_{z}\right)=z \wedge * \operatorname{TH}\left(e_{z}\right)=z\right]
\end{aligned}
$$

Whether or not reflexivity necessarily holds at the atomic level, is determined by the "plural properties" of the relations involved (Langendoen and Magloire 2003:48). There are only two types of relations for which reflexivity at the atomic level is entailed: doubly dissective (DD) and dissective-nucleative (DN) relations. A relation $R$ is doubly dissective iff $R(x, y)$ entails $\mathrm{R}\left(x_{i}, y_{i}\right)$ for all $x_{i}$ $\leq_{\mathrm{AT}} x$ and all $y_{i} \leq_{\mathrm{AT}} y$. For example, be in love with is DD because Anna and Bob are in love with Otto and Nan entails Anna is in love with Otto, Bob is in 
love with Otto, Anna is in love with Nan, Bob is in love with Nan (Langendoen and Magloire 2003:42). ${ }^{33}$ A relation $R$ is dissective-nucleative iff for all $x_{i} \leq_{\mathrm{AT}} x$ there is a $y_{i} \leq_{\mathrm{AT}} y$ such that $\mathrm{R}\left(x_{i}, y_{i}\right)$, and for all $y_{i} \leq_{\mathrm{AT}} y$ there is a $x_{i} \leq_{\mathrm{AT}} x$ such that $\mathrm{R}\left(x_{i}, y_{i}\right)$. For example, looking at is $\mathrm{DN}$ because Anna and Bob are looking at Otto and Nan entails Anna is looking at Otto and Bob is looking at Nan or Anna is looking at Nan and Bob is looking at Otto (Langendoen and Magloire 2003:42).

Kick is a DN relation: Anna and Bob kicked Otto and Nan entails Anna kicked Otto and Bob kicked Nan or Anna kicked Nan and Bob kicked Otto. Therefore, (27) amounts to (28).

$$
\text { (28) } \exists e . \forall x_{i} \leq \text { they'}^{\prime} . \exists e_{z} \leq e\left[* * \mathbf{k i c k}^{\prime}\left(e_{z}\right) \wedge * \operatorname{AG}\left(e_{z}\right)=x_{i} \wedge * \mathrm{TH}\left(e_{z}\right)=x_{i}\right]
$$

For reciprocal sentences reflexivity at the atomic level cannot be permitted, but the components of reciprocity developed so far would allow this. The semantics for $-n a$ and $-k u$ give us the representation in (29) for hayt'a-na-ku-n-ku 'They are kicking each other.'

(29) hayt'a-na-ku-n-ku $\Rightarrow$

$$
\begin{aligned}
& \exists e\left[\forall x_{i} \leq_{\mathrm{AT}} \text { they }^{\prime} . \exists z \leq \text { they }^{\prime} . \exists e_{z} \leq e\left[x_{i} \leq z \wedge \neg \mathrm{AT}\left(e_{z}\right) \wedge\right.\right. \\
& \quad * * \operatorname{kick}^{\prime}\left(e_{z}\right) \wedge * \operatorname{AG}\left(e_{z}\right)=z \wedge * \mathrm{TH}\left(e_{z}\right)=z \wedge \\
& \left.\left.\forall e^{\prime}, e^{\prime \prime} \leq_{K} e_{z}\left[e^{\prime} \neq e^{\prime \prime} \rightarrow \neg\left[<\operatorname{AG}\left(e^{\prime}\right), \operatorname{TH}\left(e^{\prime}\right)>\circ<\operatorname{AG}\left(e^{\prime \prime}\right), \operatorname{TH}\left(e^{\prime \prime}\right)>\right]\right]\right]\right]
\end{aligned}
$$

We can expand the second line in (29) to look at the individuals that make up the plural $z$ and the subevents of $e$ by applying the equivalence in (19) for **-predicates. The resulting representation is given in (30).

(30) hayt'a-na-ku-n-ku $\Rightarrow$

$$
\begin{aligned}
& \exists e\left[\forall x_{i} \leq_{\mathrm{AT}} \text { they'. } \exists z \leq \text { they }^{\prime} . \exists e_{z} \leq e\left[x_{i} \leq z \wedge \neg \mathrm{AT}\left(e_{z}\right) \wedge\right.\right. \\
& \forall x \leq_{\mathrm{AT}} z \cdot \exists x^{\prime} \leq z \cdot \exists y \leq z \cdot \exists e^{\prime} \leq e_{z}\left[x \leq x^{\prime} \wedge\right. \\
& \left.\operatorname{kick}^{\prime}\left(e^{\prime}\right) \wedge \mathrm{AG}\left(e^{\prime}\right)=x^{\prime} \wedge \mathrm{TH}\left(e^{\prime}\right)=y\right] \wedge \\
& \forall y \leq_{\mathrm{AT}} z \cdot \exists y^{\prime} \leq z \cdot \exists x \leq z \cdot \exists e^{\prime} \leq e_{z}\left[y \leq y^{\prime} \wedge\right. \\
& \left.\operatorname{kick}^{\prime}\left(e^{\prime}\right) \wedge \mathrm{AG}\left(e^{\prime}\right)=x \wedge \mathrm{TH}\left(e^{\prime}\right)=y^{\prime}\right] \wedge \\
& \left.\left.\forall e^{\prime}, e^{\prime \prime} \leq_{K} e_{z}\left[e^{\prime} \neq e^{\prime \prime} \rightarrow \neg\left[<\mathrm{AG}\left(e^{\prime}\right), \mathrm{TH}\left(e^{\prime}\right)>\circ<\mathrm{AG}\left(e^{\prime \prime}\right), \mathrm{TH}\left(e^{\prime \prime}\right)>\right]\right]\right]\right]
\end{aligned}
$$

What is missing from this representation to derive weak reciprocity proper is the condition requiring the arguments $x$ and $y$ of the subevent relation kick ${ }^{\prime}$ to be distinct. How this last ingredient of reciprocity enters the semantic representation will be discussed in the next section.

\footnotetext{
${ }^{33}$ This is Langendoen and Magloire's example, though I myself am not entirely convinced that be in love with really is DD. Thus, it seems that Anna and Bob are in love with Otto and Nan is true in a situation in which Otto and Nan make a lovely couple, but as individuals are rather detestable. Anna and Bob might be in love with the couple, but not with the individuals. A better DD verb is perhaps know.
} 


\subsection{The distinctness condition}

All accounts of reciprocity I am aware of make the distinctness condition part of the semantics of the reciprocal marker itself. For example, Langendoen's definition of weak reciprocity repeated in (31) from (2) explicitly requires that the arguments of $\mathrm{R}$ be distinct:

(31) Weak Reciprocity

$$
(\forall x \in A)(\exists y, z \in A)(x \neq y \wedge x \neq z \wedge x R y \wedge z R x)
$$

(Langendoen 1978:179)

Here, I will explore an alternative hypothesis for CQ reciprocal sentences, namely that the distinctness condition is added to any relation, unless there is an explicit operator such as reflexive $-k u$ requiring identity. This hypothesis is rooted in semantic reformulations of Principle B of the Binding Theory ("a pronoun is free in its governing category"), in particular that of Reinhart and Reuland (1993) (see also Partee and Bach (1984), Sells (1991), Kiparsky (2002), and the pragmatic Disjoint Reference Presumption of Farmer and Harnish (1987) and Levinson (2000)).

Reinhart and Reuland define Condition B on semantically reflexive predicates, that is, predicates the two (or possibly three) arguments of which are coindexed. A predicate $\mathrm{P}$ is reflexive-marked iff either $\mathrm{P}$ is lexically reflexive or one of P's arguments is a SELF anaphor (Reinhart and Reuland 1993). Given these definitions, they reformulate Condition B as (32) (also cf. Jacobson (to appear))

(32) Condition B: If a predicate is reflexive it is reflexive-marked.

From this it follows that any predicate that is not reflexive-marked is not reflexive, that is, its coarguments have to be distinct. ${ }^{34}$

In CQ, where pronouns can be freely dropped, the coarguments of a predicate are always interpreted as distinct, as shown in (33a). The only way to derive a reflexive interpretation is by adding the verbal suffix $-k u$ as in (33b).

a. Hayt'a-n.

kick-3

'(S)he kicks him/her $_{j}$.' $(i \neq j)$.

\footnotetext{
${ }^{34}$ Arguably, this condition is too strong (Philippe Schlenker, p.c.). Some speakers accept English sentences with a bound non-reflexive pronoun as in (i).

(i) Everybody (including John / John himself) hates him (=John).

For (i) to be true, hate has to have $\langle$ john,john,e $\rangle$ in its extension. Usually, such sentences are judged unacceptable, however, and it seems mainly due to the presence of the parenthetical that (i) is rescued. I therefore assume that Everybody hates him without any further overt material that explicitly includes John in the group of John-haters does not have an interpretation according to which John hates John. I furthermore assume for now that the parenthetical even without the reflexive pronoun constitutes a form of reflexive-marking, but have nothing more concrete to say about how this comes about.
} 
b. Hayt'a-ku-n.

kick-REFL-3

'(S)he kicks her-/himself $_{i}$.'

Returning to reciprocal verbs, the idea is that Condition B applies to the atomic predicates $\left(\mathbf{k i c k}^{\prime}\right)$ in $(30)$, resulting in (34).

(34) hayt'a-na-ku-n-ku $\Rightarrow$

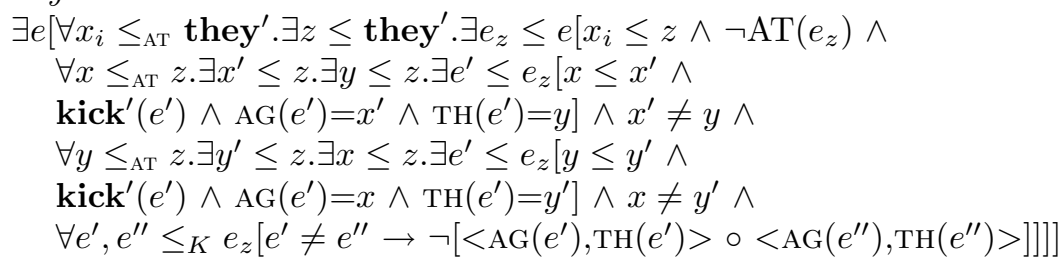

For (34) to be a valid derivation it has to be shown that the atomic predicates are not reflexive marked despite $-k u$ being present. As argued above, $-k u$ marks the cumulative predicate $* * \mathbf{k i c k}^{\prime}$ as reflexive, see e.g. (29). What has to be shown therefore is that reflexivity at this level does not entail reflexivity at the atomic level in the case of the reciprocal interpretation of verbs marked with - na, even in cases in which this is entailed for the base predicate such as hayt'a. As we have seen above, only DN and DD predicates entail reflexivity at the atomic level. Thus, only if $\mathrm{PA}(\mathrm{R})$ predicates are $\mathrm{DN}$ or $\mathrm{DD}$ will the corresponding singular predicates also be necessarily reflexive. However, $\mathrm{PA}(\mathrm{R})$ predicates are neither DN or DD, even in cases in which the base predicate is. This can easily be seen by looking at the extension of $\mathrm{PA}\left(* * \mathbf{k i c k}^{\prime}\right)$ in $(25)$, which does not contain any events with atomic agents or themes. While the plural individual $a \oplus b$ is an agent in $\mathrm{PA}\left(* * \mathbf{k i c k}^{\prime}\right), a$ and $b$ individually are not. Since (25) is a perfectly legitimate extension for a $\mathrm{PA}(\mathrm{R})$ predicate (though such a predicate may of course have atomic agents or themes), PA-predicates do not have the DN or DD entailments. Consequently, the atomic predicates in (30) are not reflexive marked and the distinctness condition is added as shown in (34).

While reflexivity at the atomic level is not entailed for pluractional predicates, it is interesting to consider the case in which $z$ equals atomic $x_{i}$ 's, that is, the case in which the reference to intermediate individuals is eliminated. The representation for hayt'anakunku with this assumption is given in (35).

(35) hayt'a-na-ku-n-ku, $z=x_{i} \Rightarrow$

$$
\begin{aligned}
& \exists e\left[\forall x_{i} \leq_{\mathrm{AT}} \text { they }^{\prime} . \exists e_{i} \leq e\left[\neg \mathrm{AT}\left(e_{i}\right) \wedge * * \operatorname{kick}^{\prime}\left(e_{i}\right)\right.\right. \\
& \wedge * \operatorname{AG}\left(e_{i}\right)=x_{i} \wedge * \mathrm{TH}\left(e_{i}\right)=x_{i} \wedge \\
& \left.\left.\forall e^{\prime}, e^{\prime \prime} \leq_{K} e_{i}\left[e^{\prime} \neq e^{\prime \prime} \rightarrow \neg\left[f\left(e^{\prime}\right) \circ f\left(e^{\prime \prime}\right)\right]\right]\right]\right]
\end{aligned}
$$

Since the $x_{i}$ 's are atoms, (35) claims that every member of they' is both the agent and theme of a plural event of kicking. This plural event can obviously not be a reciprocal event, since it will not be possible to require the agent and theme of its subevents to be distinct. What (35) shows is that sentences 
containing -na and - $k u$ should have a meaning in which each member of the subject group acts on her- or himself repeatedly (with $f=$ temporal trace function), or in different locations (with $f=$ spatial trace function). That is, (35) should have a meaning in which each member of they' kicks him-/herself repeatedly. However, consultants are extremely reluctant to accept (35) as an appropriate description of this situation. It can only mean that they are kicking each other. As mentioned in footnote 29, my hypothesis for why these predicted readings are not available empirically is that they are blocked by the existence of more specific pluractional suffixes such as the frequentive -paya.

To summarize this subsection, the distinctness condition is added to any predicate unless there is an overt marker requiring identity of coarguments. It was shown that despite $-k u$ marking the plural event denoted by a verb containing - $n a$ as reflexive, this does not entail reflexivity at the atomic subevent level. All the ingredients for deriving reciprocity are now in place: to derive the reciprocal interpretation of a verb form containing $-n a$ and $-k u$, pluractional -na requires plural events, the subevents of which are distinguished by having distinct agent/theme pairs, reflexive $-k u$ identifies the coarguments of the plural predicate, the distinctness condition is added at the level of atomic subevents, and universal quantification over the atoms making up the group denoted by the subject is a direct consequence of plural predication.

\subsection{Reciprocity with only $-k u$ and with only $-n a$}

The attentive reader will have spotted that the analysis developed so far predicts that a reciprocal interpretation should be possible with $-k u$ alone for some predicates. For DN and DD predicates such as hayt' $a$-, this interpretation is excluded because they entail reflexivity for atoms preventing the distinctness condition from being added. However, for predicates such as defend reflexivity at the level of atoms is not entailed. When the intermediate individual $z$ equals $x$, the sum individual denoted by the subject NP, in the Reflexivity Criterion, there is nothing to prevent the distinctness condition from being added in the same way as discussed in the previous section for hayt'anaku-. Moreover, because I have assumed throughout that verbs are interpreted cumulatively, a verb marked only with $-k u$ allows a plural event interpretation even without the condition introduced by $-n a$ that $\neg \mathrm{AT}(e)$. Likewise, there is nothing to prevent that the subevents are distinguished by having distinct agent/theme pairs. Thus, a sentence such as difiendi-ku-n-ku 'They defend themselves' would not only come out true in a situation in which each defended him-/herself or in which subgroups of 'they' defended themselves, but also in a situation in which they defended each other. This is not usually an interpretation that consultants agree to being available. ${ }^{35}$ That the combination of $-n a$ and $-k u$ is practically

\footnotetext{
${ }^{35}$ However, the almost identical examples in (i) and (ii) appear in a written text.

(i) ayllu uhu-pi kuska-manta warmi qhari kamachi-ku-yku family/clan interior-LOC together-ABL woman man give.orders-REFL-1EXCL 'Within the family, between wife and husband we give orders to each other.' (dentro del ayllu entre varón y mujer nos ordenamos mutuamente (Espinoza 1997:60)
} 
always preferred for expressing reciprocity even with predicates that, according to the present analysis, should allow a reciprocal interpretation with only $-k u$, is hypothesized to be due to the fact that $-k u$ by itself does not entail plurality of events or distinct agent/theme pairs for the subevents, both essential ingredients of reciprocity. The conversational principle of maximizing informativeness (Grice 1989) within the grammatically possible space seems to be very strong for my consultants, that is, it appears that they require a grammatical marker such as - na to be present if that marker disambiguates an otherwise ambiguous sentence. ${ }^{36}$ What I mean here by 'grammatically possible space' will become clear in the following discussion of reciprocity in the absence of $-k u$.

As mentioned in section 2, example (5), -na by itself can be interpreted reciprocally when it occurs preceding the causative suffix or when the verb is used as a passive participle. However, in the absence of $-k u$, the current formulation of Condition B would require the coarguments of the top-level plural verb to be non-identical as well, thus not permitting a reciprocal interpretation. In this context, it is relevant that $-k u$ can in fact not occur before the causative suffix or in passive participles, that is, the forms *hayt'akusqa (intended: 'to be kicked by oneself') and *hayt'akuchin (intended: (s)he caused someone to kick her-/himself) are ungrammatical (cf. van de Kerke (1996:180)). ${ }^{37}$ This suggests

(ii) warmi qhari uhu-pi-qa kuska-manta kamachi-ku-yku woman man interior-LOC-TOP together-ABL give.orders-REFL-1EXCL

'Within the relationship of husband and wife we give each other orders.' (Al interior de la relación entre marido y mujer nos damos órdenes mutuamente)

(Espinoza 1997:182)

The Spanish translations and surrounding context of these sentences make clear that a reciprocal interpretation is intended. Of the three consultants I have presented (i) to, two outright rejected a reciprocal interpretation. However, a third consultant at first accepted (i) with a reciprocal interpretation. Only when explicitly asked to compare it to the same sentence with - na added, did she retract her initial judgment of (i) as reciprocal. The example (ii) is followed almost immediately by roughly the same sentence, but this time with - na, without there being a detectable meaning difference between the two. It might be the case that the absence of $-n a$ in these examples is a transcription or speaker error, though this is perhaps made less likely by the fact that there are two instances. However, attempts to elicit other such examples have so far failed. It is therefore unclear whether or not some speakers allow $-k u$ on its own to describe reciprocal situations.

${ }^{36}$ This same pragmatic constraint may also explain why in most, if not all cases, an explicit distributive marker such as $-n k a$ is required to derive distributive interpretations of sentences such as (22). Making this a pragmatic rather than a semantic constraint would explain why some of Hastings' consultants allow this reading for some examples without - nka (see footnote $25)$.

In this context it is interesting that this constraint does not seem to hold for languages which use a reflexive pronoun also to express reciprocity such as the Romance languages. Thus, Spanish or French sentences with se can be disambiguated to the reciprocal interpretation by the addition of el uno al otro/l'un l'autre 'the one the other', but these are regularly omitted. This difference might have to do with the fact that the disambiguating elements are lexical expressions, whereas in CQ disambiguating - na is a bound suffix.

${ }^{37}$ For a possible explanation of why $-k u$ is ungrammatical in these contexts, I refer to van de Kerke (1996). Briefly, van de Kerke analyzes $-k u$ as an operator on argument structure which co-indexes an internal argument with the external argument (p. 159). Passive participles do not require an external argument and hence are incompatible with $-k u$. The causative $-c h i$ is incompatible with $-k u$ under the assumption that causative formation is a lexical operation 
that - na can only convey reciprocity by itself when there are independent reasons preventing $-k u$ from cooccurring with it. That is, we have to allow for identity of coarguments just in case adding a reflexive marker is not possible for grammatical reasons, and I therefore propose the following reformulation of Condition B. ${ }^{38}$

(36) Condition B: If a predicate is reflexive it is reflexive-marked, unless reflexive marking is ungrammatical for independent reasons.

With this revision of Condition $\mathrm{B},-n a$ by itself can give rise to a reciprocal interpretation just in case the addition of $-k u$ is ungrammatical.

In sum, the analysis predicts that some verb forms containing only $-k u$ should be able to truthfully describe a reciprocal situation, in addition to purely reflexive situations. I hypothesize that this is impossible for most consultants because of a strong pragmatic requirement that a disambiguating marker, in this case $-n a$, should be added whenever this is grammatically possible. In contrast, - na on its own can convey reciprocity, but only when the addition of the reflexive marker $-k u$ would be impossible.

\section{Conclusion}

I have proposed an analysis of Cuzco Quechua reciprocal sentences which derives reciprocity from pluractionality and reflexivity, both overtly marked by verbal suffixes. Universal quantification over parts of the plural agent and the requirement that the arguments in the reciprocal subevents are distinct follow from assumptions independently made in the literature, namely (i) plural predication and plural thematic roles (Sternefeld 1998, Landman 2000, Beck 2001), and (ii) a semantic formulation of Condition B (Reinhart and Reuland 1993).

(in the Southern Quechua varieties only) which demotes the causee to an internal argument.

${ }^{38}$ Philippe Schlenker (p.c.) points out that this condition might be too weak. In French, for example, the verb sembler 'seem' cannot be reflexivized (i), but Condition B effects can nevertheless be observed (ii).

(i) $* \mathrm{Jean}_{i} \mathrm{se}_{i}$ semble heureux Jean seems happy (*to himself)

(ii) $\operatorname{Jean}_{i} \operatorname{lui}_{j / * i}$ semble heureux.

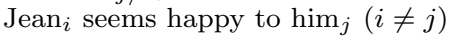

The difference between French 'sembler' and the issue just discussed for CQ is that 'sembler' appears to disallow reflexivity in any circumstance, whereas the CQ predicates allow reflexivity in principle. We might therefore want to limit Condition B to predicates that can be reflexive as well as non-reflexive. Let's introduce a feature [+/-refl] and assume that verbs like 'sembler' are lexically marked as [-refl].

(iii) Condition B:

(a) A [-refl] predicate is non-reflexive.

(b) If a $[+/-$ refl $]$ predicate is reflexive it is reflexive-marked, unless reflexive marking is ungrammatical for independent reasons. 
As should be clear from the comments I have made along the way, the main shortcoming of the particular analysis presented here for CQ is that it appears to overgenerate considerably. I say 'appears' because it is not yet entirely clear that those readings which are predicted to exist by the analysis but which I have not been able to confirm empirically, are indeed impossible. Assuming that this is so, however, I hypothesize that the absence of these readings is due to constraints on language use. Thus, the fact that the marker $-n a$ is only rarely being used for expressing temporal pluractionality may be explained by appealing to the principle of maximizing informativeness: CQ has a dedicated morpheme, -paya, which expresses this notion and which therefore preempts the use of the less specific and less informative $-n a$ in most cases. Similarly, the fact that the reflexive marker $-k u$ on its own cannot normally convey reciprocity may be explained this way. $-n a$ eliminates those readings available for $-k u$ which only involve a single event, $-n a-k u$ is therefore more specific and informative than just $-k u$. An investigation of how exactly such pragmatic principles interact with the set of data discussed in this paper will be left for future research.

Other aspects of the semantics of reciprocity in Cuzco Quechua that the current paper has not touched on, but which are of interest for future investigation are the question of how many truth-conditionally distinct readings can be identified for this language, whether or not the reciprocal construction gives rise to such scope ambiguities as discussed for example by Dalrymple et al. (1998), and the different ways of encoding the reciprocal agents, that is, either as a plural NP, (3b), or as a subject NP together with a comitative NP, (3c), which, as argued by Dimitriadis (2004) for other languages, may also lead to meaning differences.

In addition to providing a formal analysis of reciprocity in Cuzco Quechua, the main contribution of the present paper is to cross-linguistic semantics, suggesting at least the following conclusions and hypotheses. First, reciprocity is indeed partly derivable from plurality more generally, as has been argued by Langendoen (1978), Sternefeld (1998) and Beck (2001) for English. In CQ, this does not only involve nominal plurality, but also verbal plurality. A plausible cross-linguistic hypothesis is that pluractionality may also play a role in the composition of reciprocity in other languages with verbal reciprocals. Second, we may hypothesize that the distinctness condition is also not encoded directly by reciprocal constructions in other languages but derivable from Condition B, in particular in languages which do not employ an element such as English 'other' which wears distinctness on its semantic sleeve. Third, while reciprocity involves the same semantic components cross-linguistically, languages can vary considerably in the way they compose this complex semantic concept. Some languages, e.g. Chichewa, employ a dedicated reciprocal marker, which does not in any obvious way express one or more of the ingredients of reciprocity, though in such languages it may also well be the case that universal quantification and distinctness derive from independent principles. Other languages employ markers which directly encode one of the reciprocal ingredients, e.g. reflexivity in $\mathrm{CQ}$ or the Romance languages. The compositional derivation of reciprocity is therefore a clear case for cross-linguistic semantic variation. An 
interesting research question for the future is to identify the possible semantic space of variation and its cross-linguistic morphosyntactic realizations.

\author{
Author's address \\ School of Languages, Linguistics, and Cultures \\ The University of Manchester \\ Manchester M13 9PL \\ United Kingdom \\ martina.faller@manchester.ac.uk
}

\title{
Acknowledgements
}

I am very grateful to my ever patient consultants in and around Cuzco, Peru, Inés Callalli Villafuerte, Gloria Canal, Natalia Pumayalli Pumayalli, and Edith Zevallos Apaza. I thank three anonymous reviewers and Philippe Schlenker for providing challenging comments on an earlier version of this paper which helped me to sharpen the analysis. Any remaining errors are mine. I also wish to thank the audiences at SULA 2005 and at the Workshop on Formal Semantics and Cross-linguistic Data held at ESSLLI 2005 for a stimulating discussion. Two preliminary versions of this paper have been published in the respective conference proceedings. The financial support of the British Academy for fieldwork during the summer of 2004 in Cuzco, Peru, and for travel to SULA 2005 is gratefully acknowledged. Some of the data were collected and confirmed during fieldwork in 2006 funded by a grant by the Faculty of Humanities, The University of Manchester. I also thank the Max Planck Institute for Psycholinguistics in Nijmegen for allowing me to use a set of video stimuli developed for eliciting reciprocal data within the joint project with the University of Melbourne Reciprocals across Languages.

\section{References}

Beck, Sigrid (2001), Reciprocals are definites. Natural Language Semantics 9:69-138.

Bruening, Benjamin (2006), The morphosyntax and semantics of verbal reciprocals. Unpublished MS., University of Delaware, available at: http://www.ling.udel.edu/bruening/home/Reciprocals5.pdf.

Cerrón Palomino, Rodolfo (1976), Gramática Quechua Junin-Huanca. IEP. Lima.

Corbett, Greville (2000), Number. Cambridge University Press. Cambridge.

Cusihuaman, Antonio (2001), Gramática Quechua: Cuzco-Collao. Centro de Estudios Regionales Andinos "Bartolomé de las Casas". Cuzco. (Second edition, first published in 1976). 
Dalrymple, Mary, Makoto Kanazawa, Yookyung Kim, Sam Mchombo, and Stanley Peters (1998), Reciprocal expressions and the concept of reciprocity. Linguistics and Philosophy 21:159-210.

Dalrymple, Mary, Sam Mchombo, and Stanley Peters (1994), Semantic similarities and syntactic contrasts between Chichewa and English reciprocals. Linguistic Inquiry 25(1):145-163.

Dimitriadis, Alexis (2004), Discontinous reciprocals. Unpublished MS., Utrecht Institute of Linguistics OTS.

Espinoza, Darío (1997), Tanteo puntun chaykuna valen. CHIRAPAQ-Centro de Culturas Indias. Lima. (Transcription and translation into Spanish of an autobiographical narration by Ciprian Phuturi Suni).

Faller, Martina (2001), The problem of Quechua - nka-distributivity vs. group forming. In J.-Y. Kim and A. Werle (eds.), Proceedings of SULA. Amherst. $38-46$.

Faller, Martina (2005), The ingredients of reciprocity in Cusco Quechua. In H. de Hoop and J. Zwarts (eds.), Proceedings of the ESSLLI'05 workshop on Formal Semantics and Cross-Linguistic Data. Edinburgh.

Faller, Martina (to appear), Reciprocity without reciprocals: a case study of Cusco Quechua. In M. Becker and A. McKenzie (eds.), Proceedings of SULA 3. Amherst.

Farmer, A. and M. Harnish (1987), Communicative reference with pronouns. In J. Verschueren and M. Bertuccelli-Papi (eds.), The pragmatic perspective. John Benjamins. Amsterdam. 547-565.

Federación Agraria Revolucionaria Túpac Amaru II del Cusco FARTAC (ed.) (2002), Voz y Opinión de la mujer andina-Kallpa kananpaq. FARTAC. Cusco.

Fiengo, Robert, and Howard Lasnik (1972), The logical structure of reciprocal sentences in English. Foundations of Language 9:447-468.

Grice, Paul (1989), Studies in the Way of Words. Harvard University Press. Cambridge.

Itier, César (ed.) (1999), Karu Nankunapi. Centro de Estudios Regionales Andinos "Bartolomé de Las Casas". Cusco.

Jacobson, Pauline (to appear), Direct compositionality and variable free semantics: The case of "Principle B" effects. In C. Barker and P. Jacobson (eds.), Direct Compositionality, Oxford Studies in Theoretical Linguistics. OUP. Oxford.

van de Kerke, Simon (1996), Affix Order and Interpretation in Bolivian Quechua. Ph.D. thesis. University of Amsterdam.

Kiparsky, Paul (2002), Disjoint reference and the typology of pronouns. In I. Kaufmann and B. Stiebels (eds.), More than Words, Vol. 53 of Studia Grammatica. Akademie Verlag. Berlin. 179-226.

Kratzer, Angelika (to appear), On the plurality of verbs. In J. Dölling and T. Heyde-Zybatow (eds.), Event Structures in Linguistic Form and Interpretation. Mouton de Gruyter. Berlin. 
Krifka, Manfred (1992), Thematic relations as links between nominal reference and temporal constitution. In I. Sag and A. Szabolsci (eds.), Lexical Matters. CSLI. Stanford. 29-53.

Krifka, Manfred (1998), The origins of telicity. In S. Rothstein (ed.), Events and Grammar. Kluwer Academic Publishers. Dordrecht. 197-235.

Krikfa, Manfred (1982), Nominalreferenz und Zeitkonstitution: Zur Semantic von Massentermen, Pluraltermen und Aspektklassen. Wilhelm Finck. Munich. Ph.D. Dissertation. University of Munich.

Landman, Fred (1996), Plurality. In S. Lappin (ed.), The Handbook of Contemporary Semantic Theory. Blackwell. Oxford. 425-457.

Landman, Fred (2000), Events and Plurality. The Jerusalem Lectures. Kluwer Academic Publishers. Dordrecht.

Langendoen, D. Terence, and Joël Magloire (2003), The logic of reflexivity and reciprocity. In A. Barss (ed.), Anaphora: A Guidebook. Blackwell Publishing. Oxford. 237-263.

Langendoen, T (1978), The logic of reciprocity. Linguistic Inquiry 9:177-197.

Lasersohn, Peter (1995), Plurality, Conjunction and Events. Kluwer. Dordrecht.

Levinson, Steven C. (2000), Presumptive Meanings: The Theory of Generalized Conversational Implicature. MIT Press. Cambridge.

Link, Godehard (1998), Algebraic Semantics in Language and Philosophy. Vol. 74. CSLI Publications, Lecture Notes. Stanford.

Matthewson, Lisa (2000), On distributivity and pluractionality. In SALT X. CLC Publications. Cornell.

Mchombo, Sam A. (1993), On the binding of the reflexive and the reciprocal in Chichewa. In S. A. Mchombo (ed.), Theoretical Aspects of Bantu Grammar. Leland Stanford Junior University. Stanford. 181-207.

Muysken, Pieter (1981), Quechua causatives and logical form: a case study in markedness. In A. Belletti, L. Brandi, and L. Rizzi (eds.), Theory of Markedness in Generative Grammar: proceedings of the 1979 GLOW conference. Scuola Normale Superiore di Pisa. Pisa. 445-473.

Newman, Paul (1990), Nominal and Verbal Plurality in Chadic. Foris. Dordrecht.

Partee, Barbara, and Emmon Bach (1984), Quantification, pronouns, and VP anaphora. In J. Groenendijk, T. M. V. Janssen, and M. Stokhof (eds.), Truth, Interpretation and Information, selected papers from the 3rd Amsterdam Colloquium, Groningen-Amsterdam Studies in Semantics. Foris Publications. Groningen-Amsterdam.

Reinhart, Tanya, and Eric Reuland (1993), Reflexivity. Linguistic Inquiry 28:178-187.

Rullmann, Hotze, and Aili You (2003), General number and the semantics and pragmatics of indefinite bare nouns in Mandarin Chinese. Unpublished MS.

Schwarzschild, Roger (1996), Pluralities. Kluwer Academic Publishers. Dordrecht. 
Sells, Peter (1991), Disjoint reference into NP. Linguistics and Philosophy 14:151-169.

Siloni, Tal (to appear), The syntax of reciprocal verbs: an overview. In E. König and V. Gast (eds.), Reciprocals and Reflexives: Cross-linguistic and theoretical explorations, Trends in Linguistics. Mouton de Gruyter. Berlin.

Sternefeld, Wolfgang (1998), Reciprocity and cumulative predication. Natural Language Semantics 6:303-337.

Valderrama Fernandez, R., and C. Escalante Gutierrez (1982), Gregorio Condori Mamani, Autobiografia. Centro de Estudios Rurales Andinos "Bartolomé de Las Casas". Cusco.

Vengoa Zúñiga, Janett (ed.) (1998), Cúentos Campesinos. Centro de Estudios Regionales Andinos Bartolomé de las Casas. Cusco. 